\title{
The Influence of Vitamin D Metabolism on Gene Expression, Matrix Production and Mineralization During Osteoprecursor Cell-Based Bone Development
}

\author{
Shelley S. Mason ${ }^{\mathrm{a}, \mathrm{b}}$, Sean S. Kohles ${ }^{\mathrm{a}, \mathrm{c}, \mathrm{e}}$, Shelley R. Winn ${ }^{\mathrm{c}, \mathrm{d}}$, Randy D. Zelick
}

\begin{abstract}
Background: Multipotential precursor cell lines derived from human bone marrow, capable of differentiating into cartilage or bone, may provide a useful tissue development model for studying the regulation and metabolism of putative growth and differentiation factors necessary for tissue regeneration. In mammals, the process of bone development depends on the proliferation and differentiation of osteoblast lineage cells, and the subsequent synthesis and mineralization of bone extracellular matrix (ECM). Vitamin D metabolites play a pivotal role in bone and mineral homeostasis, and are positive factors on bone development. Recently, it was demonstrated that a human-derived engineered osteoblast precursor cell line (OPC1), derived from human bone marrow, can metabolize the parental precursor vitamin $\mathrm{D}_{3}\left(\operatorname{vitaD}_{3}\right)$ to the active steroid $1 \alpha, 25$-dihydroxyvitamin $\mathrm{D}_{3}\left(1,25 \mathrm{OH}_{2} \mathrm{D}_{3}\right)$, and elicit an osteogenic response that results in the decrease in proliferation and increase in ECM synthesis during early bone development. The aim in this study is to characterize gene expression, matrix production and mineralization within a bone development model.
\end{abstract}

Methods: We investigated whether vitaD $\mathrm{D}_{3}$ influences bone ECM mineralization in the same manner as $1,25 \mathrm{OH}_{2} \mathrm{D}_{3}$ in confluent cultures of OPC1s. In addition, we explored the influence of vitamin D metabolites, in combination with other commonly used osteogenic factors, ascorbic acid, $\beta$-glycerophosphate, dexamethasone (dex)

Manuscript accepted for publication March 25, 2014

${ }^{a}$ Department of Biology, Portland State University, Portland, Oregon, USA

${ }^{\mathrm{b}}$ Presently with the Department of Cell and Molecular Biology, Oregon

Health and Science University, Portland, Oregon, USA

${ }^{c}$ Department of Restorative Dentistry, Division of Biomaterials and Biomechanics, Oregon Health and Science University, Portland, Oregon, USA

${ }^{\mathrm{d}}$ Department of Molecular and Medical Genetics, Oregon Health and Science University, Portland, Oregon, USA

${ }^{\mathrm{e}}$ Corresponding author: Sean S. Kohles, Division of Biomaterials and Biomechanics, Department of Restorative Dentistry, Oregon Health and Science University, 611 SW Campus Avenue, Portland, OR 97239, USA. Email: kohles@ohsu.edu

doi: http://dx.doi.org/10.14740/jem212w and recombinant human bone morphogenetic protein-2 (rhBMP-2) on the osteoinduction of OPC1.

Results: It was demonstrated that OPC1 expresses the mRNA for the enzymatic equipment necessary to convert vitaD $\mathrm{D}_{3}$ to $1,25 \mathrm{OH}_{2} \mathrm{D}_{3}$, as well as the mRNA expression of the catabolic enzyme known to regulate the concentration of active $1,25 \mathrm{OH}_{2} \mathrm{D}_{3}$. It was also demonstrated that mRNA expression for the vitamin $\mathrm{D}$ receptor (VDR) was influenced by both vitaD $\mathrm{D}_{3}$ and $1,25 \mathrm{OH}_{2} \mathrm{D}_{3}$. Differential results using vitamin $\mathrm{D}$ metabolites in combination with ascorbic acid, $\beta$-glycerophosphate, dex and/or rhBMP-2 were observed in alkaline phosphatase (ALP) activity and calcium deposition, and mRNA expression of procollagen type I (proColI), osteocalcin (OC) and osteopontin (OP).

Conclusions: Overall it was demonstrated that vitamin D in combination with osteogenic factors influences the temporal bone development sequence in a positive manner.

Keywords: Cell and tissue engineering; Osteoinduction; Osteogenic factors; Stem cells; Mesenchymal stromal cells; Cholecalciferol; Calcitriol

\section{Introduction}

Most of the load-bearing demand placed on the human body is transduced by skeletal tissue, and the skeleton's capacity to articulate is essential for mobility and locomotion [1]. Consequently, cartilage and bone defects due to trauma, disease and developmental abnormalities may result in severe disabling pain and immobility for millions of people worldwide [2]. Multipotential precursor cell lines derived from human bone marrow, capable of differentiating into cartilage or bone, may provide a useful tissue development model for studying the regulation and metabolism of putative growth and differentiation factors necessary for tissue regeneration.

There are several factors that need to be taken into consideration for in vitro model systems, such as cell source and acquisition, phenotypic stability, reproducibility and the incorporation of appropriate signaling molecules. One of the challenges in using mesenchymal stromal cells (MSCs), 
Table 1. Oligionucleotide Single-Stranded Molecular Primers Used in Quantitative, Real-Time RT-PCR

\begin{tabular}{|c|c|c|}
\hline Primer set & Forward & Reverse \\
\hline CYP24A1 & 5' - GCA GCC TAG TGC AGA TTT - 3' & 5' - ATT CAC CCA GAA CTG TTG - 3' \\
\hline CYP27A1 & 5' - GGC AAG TAC CCA GTA CGG - 3' & 5' - AGC AAA TAG CTT CCA AGG - 3' \\
\hline CYP27B1 & 5' - TGT TTG CAT TTG CTC AGA - 3' & 5' - CCG GGA GAG CTC ATA CAG - 3' \\
\hline VDR & 5’ - CCA GTT CGT GTG AAT GAT GG - 3’ & 5' - GTC GTC GGT GAA GGA - 3' \\
\hline OC/BGLAP & 5' - CTG GCC ACT GCA TTC TGC - 3' & 5' - AAC GGT GGT GCC ATA GAT GCG - 3' \\
\hline OP/SPP1 & 5' - AAA TAC CCA GAT GTG GC - 3' & 5' - AAC CAC ACT ACC TCG GC - 3' \\
\hline Pro-ColI & 5' - TGA CGA GAC CAA GAA CTG - 3' & $5^{\prime}$ - CCA AAG TCA CCA AAC CTA CC - 3' \\
\hline
\end{tabular}

or progenitor cells isolated from bone marrow aspirates, is isolation sufficiency and expansion. This is due to the relatively low frequency at which these cells exist in the marrow stroma (reported to be in the range of 1/10,000 cells to $1 / 100,000$ cells) $[1,3,4]$. In addition, MSCs have a finite capacity for self-renewal, and the potential to proliferate and differentiate diminishes with age. MSC isolates also tend to be heterogeneous, containing progenitor cells with varying levels of potency. By contrast, the osteoblastic precursor cell line (OPC1) is a conditionally immortalized cell line derived from human bone, and has been demonstrated to maintain phenotypic stability and a consistent pattern of differentiation for more than 70 passages, providing an ideal model for the study of osteoblast differentiation and bone development as an alternative to MSCs [5]. We have used the OPC1 in a previous study and have shown it to provide a consistent and reproducible culture system for evaluating bone development [6]. We were able to demonstrate the extra-endocrine metabolism of vitamin $\mathrm{D}_{3}($ vitaD $)$ to $1 \alpha, 25$-dihydroxyvitamin $\mathrm{D}_{3}\left(1,25 \mathrm{OH}_{2} \mathrm{D}_{3}\right)$ by OPC1, which resulted in decreased proliferation and increased alkaline phosphatase (ALP) activity and calcium deposition associated with extracellular matrix (ECM) bone maturation and mineralization.

In the early $1900 \mathrm{~s}$, vitamin D was the fourth identified essential vitamin, thus named vitamin " $\mathrm{D}$ " by convention. It was not until 50 years later that it was realized that vitamin D is metabolized and acts as a steroid hormone in an endocrine manner, a paradigm that has dominated the classic thought of vitamin D function until the end of the 20th century [7]. Recently, it has been demonstrated that a number of organ systems are influenced by vitamin $\mathrm{D}$ in an autocrine manner, that is, $1,25 \mathrm{OH}_{2} \mathrm{D}_{3}$ is being synthesized within those cells, and/or within adjacent cells (paracrine action). While the vitamin $\mathrm{D}$ endocrine system plays a principal role in the maintenance of calcium and phosphate homeostasis, extraendocrine metabolism has been postulated to have cellular functions that include the regulation of proliferation, differ- entiation and apoptosis in many target tissues [8-11], including bone and cartilage.

$\mathrm{VitaD}_{3}$ is biologically inactive in physiologic concentrations until it is sequentially hydroxylated and the polarity is increased. $\mathrm{VitaD}_{3}$ is activated by two-sequential hydroxylations, first by the cytochrome P450 oxidase (CYP) 25-hydroxylase, CYP27A1 (mitochondrial) and CYP2R1 (microsomal), resulting in the metabolite 25-hydroxyvitamin $\mathrm{D}_{3}$ $\left(25 \mathrm{OHD}_{3}\right)$, and then to the active metabolite, $1,25 \mathrm{OH}_{2} \mathrm{D}_{3}$, by 25-hydroxyvitaminD $\mathrm{D}_{3}-1 \alpha$-hydroxylase (CYP27B1) [10, 1214].

$1,25 \mathrm{OH}_{2} \mathrm{D}_{3}$ is the most active form of vitamin $\mathrm{D}$ because of its high affinity for the intranuclear vitamin $\mathrm{D}$ receptor (VDR), mediating its biological influence upon binding. VDR belongs to the nuclear hormone receptor family and serves as a ligand-dependent transcription factor (TF) that controls the expression of vitamin D associated target genes which include those associated with calcium homeostasis, cellular proliferation and differentiation, cell division and cycle arrest, and apoptosis [15-19]. Upon 1,25OH2D3 binding, VDR forms a heterodimer with the retinoid $\mathrm{X}$ receptor, which allows it to bind to vitamin $\mathrm{D}$ receptor elements (VDREs) in the promoter regions of target genes [8, 14, 17, 20]. Coupled with other TFs, this complex induces transcription of vitamin D responsive genes including those associated with the CYP-related enzymes required for vitamin D metabolism [14, 17, 20-22].

The action of vitamin D is limited by the catabolic enzyme 24-hydroxylase (CYP24A1), which results in a compound that is more soluble and has a substantially lower affinity for VDR [12, 14, 23]. CYP24A1 has been shown to hydroxylate both $25 \mathrm{OHD}_{3}$ and $1,25 \mathrm{OH}_{2} \mathrm{D}_{3}$ to form $24,25 \mathrm{OH}_{2} \mathrm{D}_{3}$ and $1,24,25 \mathrm{OH}_{3} \mathrm{D}_{3}$, respectively [17]. The main function of CYP24A1 is to regulate the circulating concentration of $1,25 \mathrm{OH}_{2} \mathrm{D}_{3}$ by inactivating it. The catabolic pathway of CYP24A1, collectively known as the C-24 oxidation pathway, starts with the 24-hydroxylation of $25 \mathrm{OH}_{2} \mathrm{D}_{3}$ 
A

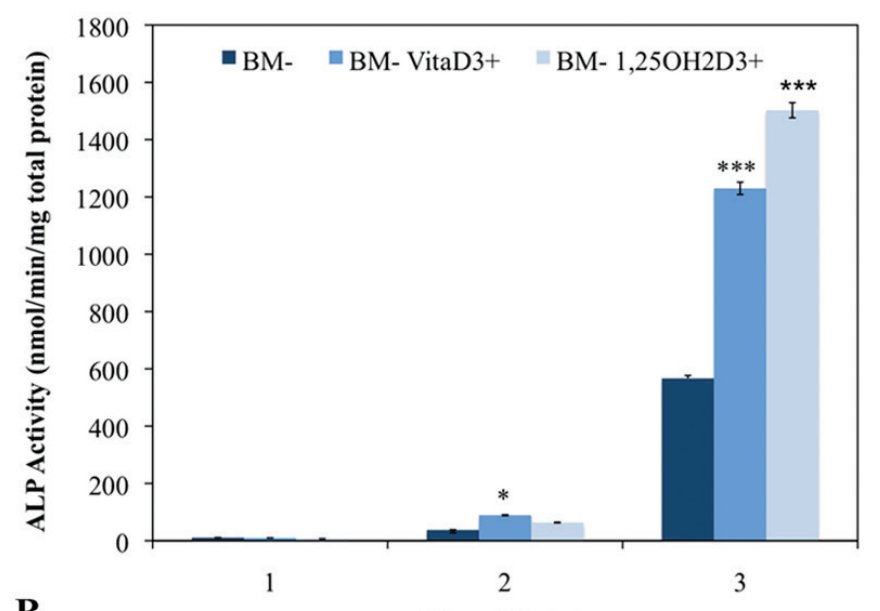

B

Time (Weeks)
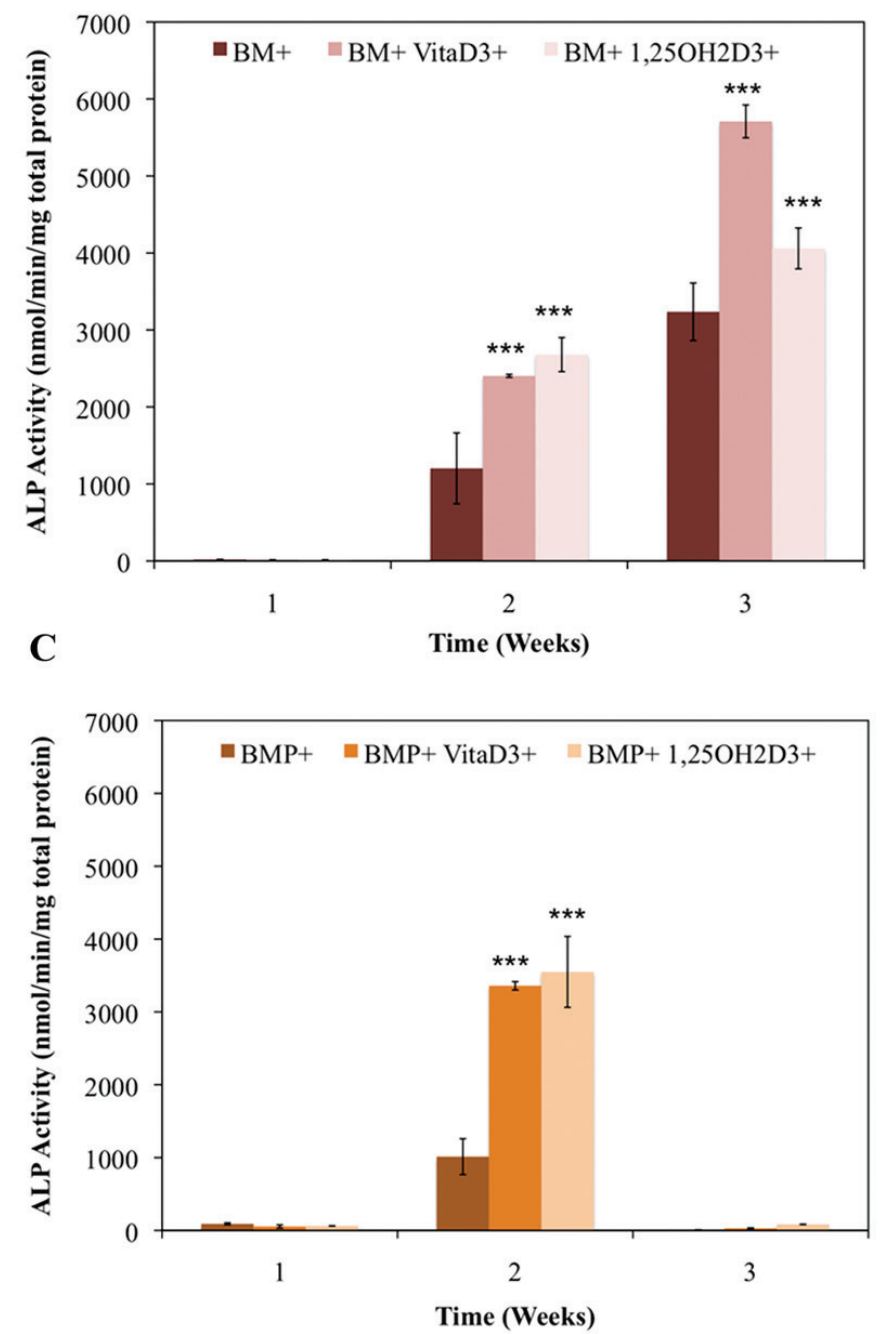

Figure 1. Temporal alkaline phosphatase activity of OPC1 treated with (A) ethanol vehicle control in standard bone medium (BM-), BM- containing vitamin $\mathrm{D}_{3}\left(\mathrm{BM}-\right.$ vitaD3+) and $\mathrm{BM}$ - with 1,25OH $\mathrm{D}_{3}(\mathrm{BM}-1,25 \mathrm{OH} 2 \mathrm{D} 3+)$; (B) ethanol control in osteogenic medium $(\mathrm{BM}+)$ containing ascorbic acid, $\beta$-glycerophosphate and dexamethasone, $\mathrm{BM}+$ containing vitamin $\mathrm{D}_{3}\left(\mathrm{BM}+\right.$ vitaD3+), and $\mathrm{BM}+$ with $1,25 \mathrm{OH}_{2} \mathrm{D}_{3}(\mathrm{BM}+$ vitaD3+); (C) ethanol control in $\mathrm{BM}+$ containing rhBMP $(\mathrm{BMP}+), \mathrm{BMP}+$ containing vitamin $\mathrm{D}_{3}\left(\mathrm{BMP}+\right.$ vitaD3+), and $\mathrm{BMP}+$ with $1,25 \mathrm{OH}_{2} \mathrm{D}_{3}(\mathrm{BMP}+$ vitaD3+). Cellular isolates were collected on day 7,14 and 21 during the differentiation time course. Treatment with both vitamin D metabolites significantly influenced OPC 1 ALP activity in all medium groups $(P<0.01)$. 


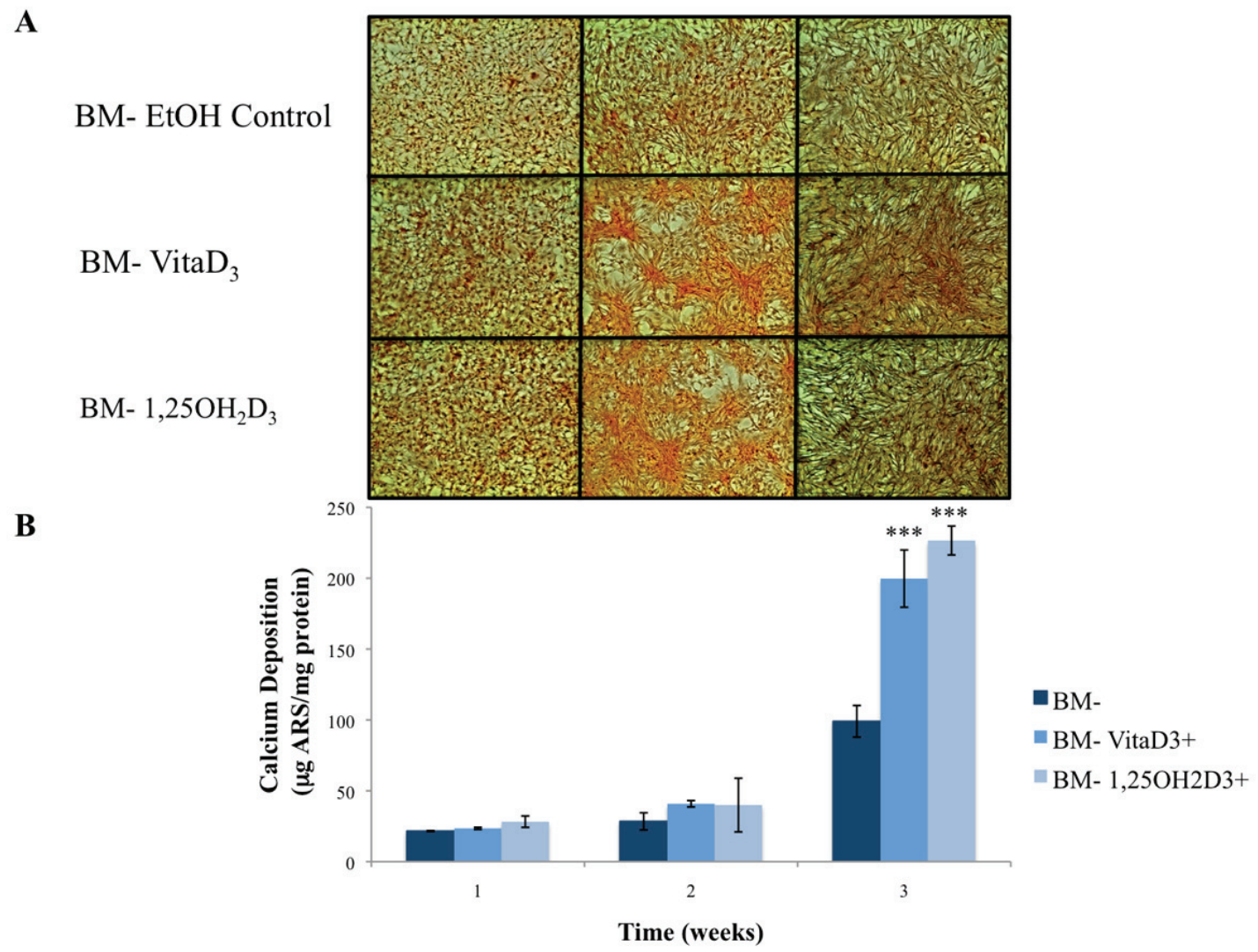

Figure 2. (A) Calcium deposition stained with alizarin red stain (ARS) of OPC1 cultured in BM- and either vitamin D metabolites, vitamin $D_{3}$ or $1,25 \mathrm{OH}_{2} \mathrm{D}_{3}$. (B) After microscopic analysis, ARS was extracted from each culture well, and quantified on a microplate reader. By week three of culture, there was a statistically larger amount of calcium deposition detected by ARS in cells treated with either vitamin $\mathrm{D}_{3}$ or $1,25 \mathrm{OH}_{2} \mathrm{D}_{3}$ compared to that of the ethanol control ( ${ }^{* * *} \mathrm{P}<0.001$ ).

or $1,25 \mathrm{OH}_{2} \mathrm{D}_{3}$ followed by sequential steps of hydroxylation that lead to the progressive loss of biological activity until vitamin $\mathrm{D}$ is converted to the water-soluble biliary excretory form, calcitroic acid $[10,12,24] .1,25 \mathrm{OH}_{2} \mathrm{D}_{3}$ induces and mediates CYP24A1 via an autocatalytic loop through VDRE located in the promoter region of the CYP24A1 gene [21]. Generally, basal expression of CYP24A1 is extremely low but the gene is highly induced by $1,25 \mathrm{OH}_{2} \mathrm{D}_{3}[11,20]$. Thus, the synthesis and degradation of $1,25 \mathrm{OH}_{2} \mathrm{D}_{3}$ is highly regulated, and the concentration is controlled at the cellular level.

Vitamin D affects many aspects of bone cell biology, and has been implicated in the regulation of both osteoblastic and osteoclastic activity influencing both resorptive and synthetic phases of bone remodeling [11]. In addition, $1,25 \mathrm{OH}_{2} \mathrm{D}_{3}$ has been demonstrated to regulate osteoblast and chondrocyte gene transcription, proliferation, differentiation and ECM maturation [11, 25]. VDR is nearly ubiquitously expressed, as almost all cells respond to $1,25 \mathrm{OH}_{2} \mathrm{D}_{3}$ [26], and it is known to regulate the function of more than 200 genes [13, 17-19].

In this study, our objective was to quantify the differenti- ation of the $\mathrm{OPC} 1$ as an osteoprogenitor along the osteoblastic lineage including the events associated with bone development in the presence of vitamin $\mathrm{D}$ metabolites, $\mathrm{vita}_{3}$ and $1,25 \mathrm{OH}_{2} \mathrm{D}_{3}$. Additional osteogenic factors included ascorbic acid, $\beta$-glycerophosphate, dexamethasone and bone morphogenetic protein-2 (BMP-2). Because in vitro temporal bone development encompasses three stages (proliferation, bone ECM maturation and mineralization) and vitamin $\mathrm{D}$ has been shown to significantly hamper OPC1 proliferation [6], confluent cultures were used in order to investigate the influence on bone ECM maturation and mineralization.

\section{Materials and Methods}

\section{Vitamin D and OPC1 cell cultures}

VitaD $_{3}$ (cholecalciferol) and $1,25 \mathrm{OH}_{2} \mathrm{D}_{3}$ (calcitriol) were purchased (Sigma-Aldrich, St. Louis, MO), and maintained in $10 \mathrm{mM}$ and $10 \mu \mathrm{M}$ stock solutions in ethanol, respectively. All other reagents and chemicals were purchased from the 


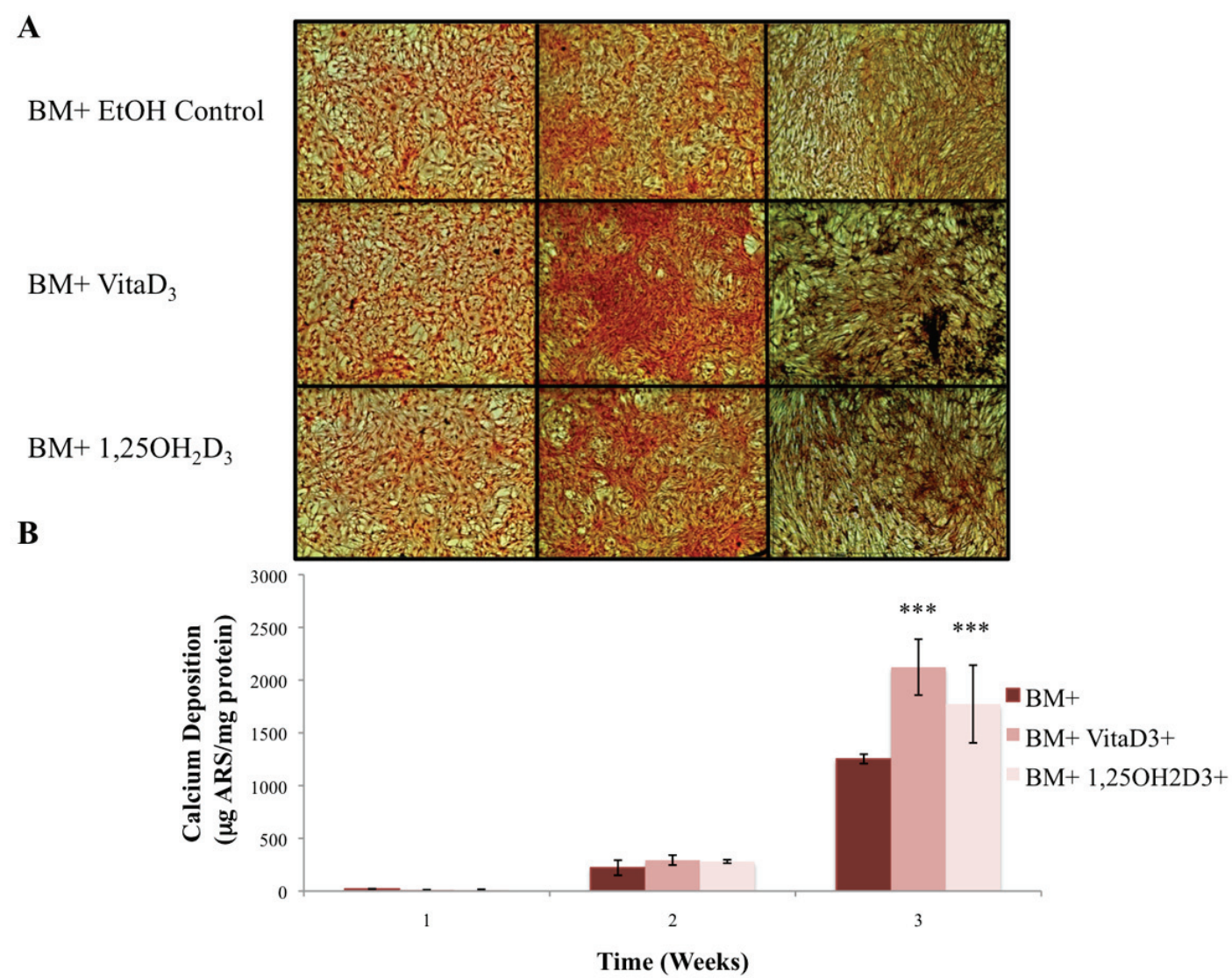

Figure 3. (A) OPC1 calcium deposition stained with ARS during culture in $B M+$ and either vitamin $D_{3}$ or $1,25 O H_{2} D_{3}$. (B) $A f t e r$ microscopic analysis, ARS was extracted from each culture well and read on a microplate reader. By week three of culture, there again was a larger amount of calcium deposition detected by ARS in cells treated with either vitamin $\mathrm{D}_{3}$ or $1,25 \mathrm{OH}_{2} \mathrm{D}_{3} \mathrm{compared} \mathrm{to}$ that of the ethanol control $\left({ }^{* * *} \mathrm{P}<0.001\right)$. In addition, there was more calcium deposition in the $\mathrm{BM}+$ treatment groups compared to all BM- groups (shown in Fig. 2).

same vendor unless otherwise indicated. Original OPC1 and rhBMP-2 were prepared and maintained locally [5].

Cells were cultured at populations of $2.5 \times 10^{5}$ in 75 $\mathrm{cm}^{2}$ tissue culture flasks in alpha modified essential medium $(\alpha$-MEM) with $5 \%$ fetal bovine serum (FBS). Once confluent, OPCs were plated in 12-well plates after trypsin-ethylenediaminetetraacetic acid (EDTA) enzymatic removal and counted with $0.4 \%$ trypan blue $(1: 1)$ on a hemacytometer. Cultures were then prepared in duplicate at a seeding density of $3.0 \times 10^{4}$ cells/well in the initial bone medium (designated as BM-) with $200 \mathrm{mM}$ L-glutamine and antibiotics until 85$90 \%$ confluent prior to adding experimental medium. Nine variations of medium were utilized in quadruplicates. BMwith $95 \%$ ethanol $(\mathrm{EtOH})$, in an amount that facilitated the EtOH as a vehicle for vitamin D metabolite delivery, provided a negative control (group 1). The additional groups

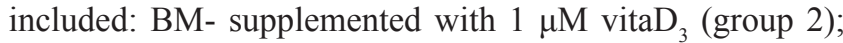
$\mathrm{BM}$ - supplemented with $10 \mathrm{nM} 1,25 \mathrm{OH}_{2} \mathrm{D}_{3}$ (group 3); BMsupplemented with osteogenic factors $(\mathrm{BM}+)$ comprised of $50 \mu \mathrm{g} / \mathrm{mL}$ ascorbic acid, $10 \mathrm{mM} \beta$-glycerophosphate, $10 \mathrm{nM}$ dexamethasone (dex) and $50 \mu \mathrm{g} / \mathrm{mL}$ of ascorbic acid phos- phate (Wako Chemical, Osaka, Japan), provided as a positive control (group 4); $\mathrm{BM}+$ supplemented with $1 \mu \mathrm{M}$ vitaD

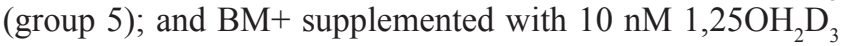
(group 6). Enhanced supplementation groups were also prepared: $\mathrm{BM}+$ supplemented with rhBMP-2 $(\mathrm{BMP}+)$ (group 7); $\mathrm{BMP}+$ with $1 \mu \mathrm{M}$ vitaD ${ }_{3}$ (group 8); and $\mathrm{BMP}+$ supplemented with $10 \mathrm{nM} 1,25 \mathrm{OH}_{2} \mathrm{D}_{3}$ (group 9). Fresh medium was added every 1 to 2 days.

\section{Bone matrix maturation}

ALP activity was monitored, as it is known to be involved with ECM maturation and mineralization through increased phosphate concentration [27]. ALP levels associated with the OPC1 response to both vitaD $\mathrm{D}_{3}$ and $1,25 \mathrm{OH}_{2} \mathrm{D}_{3}$ in $\mathrm{BM}-$-, $\mathrm{BM}+$ and $\mathrm{BMP}+$ were determined in duplicate at the previously indicated concentrations. ALP was measured every 7 days. At the end of the incubation, the cell layers were washed with cold DPBS and $500 \mu \mathrm{L} 0.1 \%$ triton-X in DPBS, then stored at $-80^{\circ} \mathrm{C}$ until the end of each experimental period. ALP activity in the cell lysates was measured using $\rho$-nitrophenyl 
$\mathbf{A}$

BMP+ EtOH Control

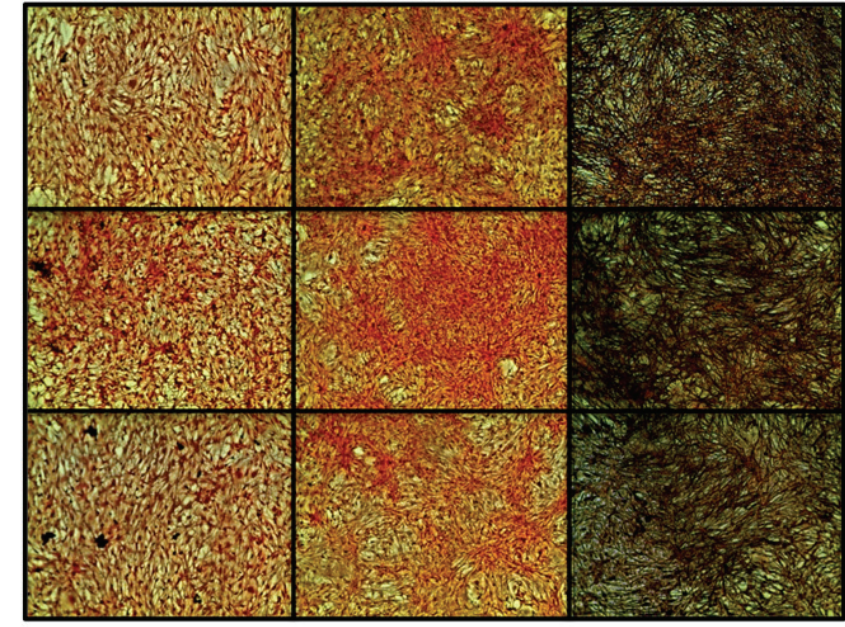

B

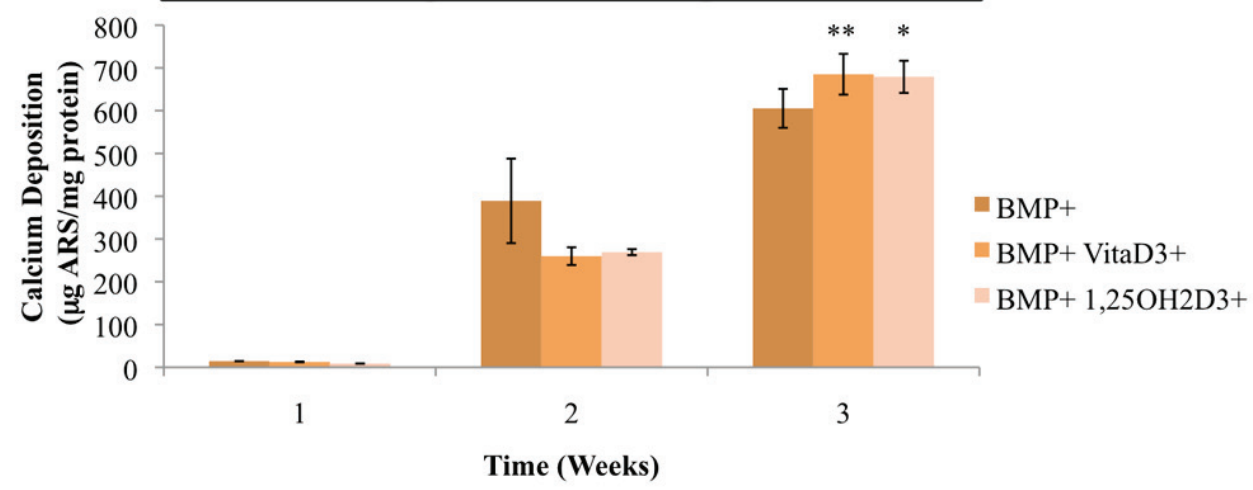

Figure 4. (A) OPC1 calcium deposition as stained with ARS during culture in BMP+ containing rhBMP-2 (BMP+) and either vitamin $\mathrm{D}_{3}$ or $1,25 \mathrm{H}_{2} \mathrm{D}_{3}$. (B) Quantified ARS as extracted from each culture well and read on a microplate reader. In the second week of culture, the BMP+ EtOH control had a larger amount of calcium deposition in comparison with the treatment groups $(P<0.05)$. By week three of culture, there was more calcium deposition detected by ARS in cells treated with either vitamin D metabolites compared to that of the ethanol control $\left({ }^{*} \mathrm{P}<0.01\right)$. In addition, there was a statistically more calcium deposition in the BMP+ treatment groups $(\mathrm{P}<0.001)$ compared to all BM- groups (plotted in Fig. 2).

phosphate liquid substrate system at $37^{\circ} \mathrm{C}$ for $30 \mathrm{~min}$. Protein content was measured using a micro-volume spectrophometer system (Epoch; Biotek, Winooski, VT).

\section{Bone matrix mineralization}

Calcium deposition was determined through a histochemical analysis of mineralization utilizing Alizarin Red S (ARS). ARS staining identified calcium-rich deposits made by the cells in culture. This approach is considered a functional in vitro endpoint reflecting advanced cell differentiation [28]. Every 7 days the cells were fixed in $10 \%$ neutral buffered formalin for 15 min followed by fixation in $100 \%$ cold methanol. Each well was rinsed thoroughly with cold DPBS, and stained with $40 \mathrm{mM}$ of ARS ( $\mathrm{pH}=4.1$ ), at room temperature for $20 \mathrm{~min}$ with gentle shaking. The cell layers were rinsed and observed both grossly and microscopically. For semi-quantification, ARS was extracted from the cells after incubating for $1 \mathrm{~h}$ at room temperature in $10 \%$ volume to volume ( $\mathrm{v} / \mathrm{v})$ acetic acid with gentle shaking, and then the residual dye was further extracted by scraping the cells and heating at $85^{\circ} \mathrm{C}$ on a heating block with a layer of mineral oil to prevent evaporation. The samples were neutralized with $10 \%(\mathrm{v} / \mathrm{v})$ ammonium hydroxide and the extracts were read at $405 \mathrm{~nm}$ on a microplate-reader (Cary 50; Varian Australia Pty. Ltd). The samples were compared to a serially diluted ARS standard. The resulting data were normalized with total protein content measured using a micro-volume spectrophometer system (Epoch; Biotek, Winooski, VT).

\section{Gene sequencing}

Quantitative real-time, reverse transcription polymerase chain reaction (RT-PCR) analysis techniques were used to characterize the activity of the genes associated with vitamin D metabolism: CYP24A1, CYP27A1, CYP27B1 and VDR $[16,29]$. In addition, RT-PCR was used to detect levels of osteopontin (OP), procollagen type I (proColI) and osteocal- 
cin (OC). These noncollagenous and collagenous proteins are associated with hydroxyapatite binding and pre-collagen synthesis, respectively, during bone development [5]. The oligionucleotide RT-PCR primer sequences (Table 1) were purchased from a commercial source (Intergrated DNA Technologies, Coralville, IA). Briefly, messenger ribonucleic acid (mRNA) was isolated using $500 \mu \mathrm{L}$ of a chemical reagent (TRIzol, Life Technologies, Grand Island, NY) per well of the 12-well plates. Samples were collected every 7 days and stored at $-80{ }^{\circ} \mathrm{C}$. The mRNA was purified according to the reagent manufacturer's specifications and the concentration was determined in units of $\mu \mathrm{g} / \mathrm{mL}$ by spectrophotometric absorbance of light at wavelengths of $260 \mathrm{~nm}$ and $280 \mathrm{~nm}$ $\left(\mathrm{A}_{260} / \mathrm{A}_{280}\right)$ (Epoch, Biotek, Winooski, VT). The complementary deoxyribonucleic acid (cDNA) was synthesized from 2 $\mu \mathrm{g}$ of the mRNA using a high capacity reverse transcriptase kit (Applied Biosystems, Life Technologies) according to manufacturer's instructions. Aliquots of the total cDNA were amplified in each PCR using fast green master mix (SYBR, Applied Biosystems, Life Technologies) with the acquired primers (Table 1). This amplification was performed in a quantitative thermocycler (Rotor-Gene Q, Qiagen, Germantown, MD) for 45 cycles $\left(30 \mathrm{sec}\right.$ denaturation at $95{ }^{\circ} \mathrm{C}, 45$ sec annealing at $58{ }^{\circ} \mathrm{C}$ and $60 \mathrm{sec}$ extension at $72{ }^{\circ} \mathrm{C}$ ).

\section{Microscopic imaging}

Microscopic images were taken using an advanced transmitted light inverted microscope and accompanying software (EVOS-XL and EVOS3, Advanced Microscopy Group, Bothell, WA). Images were processed using an open source, image-processing package (FIJI, ImageJ v1.47d, National Institutes of Health, Bethesda, MD). To maintain consistency, each image was processed in the same manner including maintaining consistent light intensities during optical density measurements. The operations (Contrast-Limited Adaptive Histogram Equalization commands) included background subtraction (blocksize 100), mean filter (bin 256) and local contrast (maximum slope 2.50).

\section{Statistical analysis}

Statistical analyses were carried out using commercial software (Prism, Irvine, CA; Excel, Microsoft, Redmond, WA). Data were expressed as means \pm standard error of the mean (SEM) of samples characterized in three 2-week sample sets plated in duplicate or quadruplicate, and assayed in duplicate $(n=12$ or $n=24$, respectively). A two-way analysis of co-variance (ANCOVA) with a Bonferonni post-test (direct comparison with controls), Dunnett's test (pairwise comparisons) and non-linear regression (polynomial quadratic function) were applied to statistically compare the treatment groups over time, with asterisks of $* \mathrm{P}<0.05, * * \mathrm{P}<0.01$, and $* * * \mathrm{P}<0.001$ indicating varying levels of statistical signifi- cance as noted in the figures.

\section{Results}

Increased ALP activity is known to be associated with osteoblast function and the matrix maturation stage of bone development. ALP activity here was found to be statistically higher $(\mathrm{P}<0.01)$ in groups cultured in standard bone medium (BM-) containing vita $\mathrm{D}_{3}$ by week two of culture, and significantly higher $(\mathrm{P}<0.001)$ in groups containing either vitaD $\mathrm{D}_{3}$ or $1,25 \mathrm{OH}_{2} \mathrm{D}_{3}$ by week three compared to the $\mathrm{BM}$ ethanol vehicle control (Fig. 1A). For groups in osteogenic medium $(\mathrm{BM}+)$ both vitamin $\mathrm{D}$ metabolites displayed statistically higher $(\mathrm{P}<0.001)$ ALP activity compared to the $\mathrm{BM}+$ EtOH control in both the second and third week (Fig. 1B). All groups cultured in $\mathrm{BM}+$ were significantly higher $(\mathrm{P}<$ 0.001) than the groups cultured in BM- during the 3-week culture period, and reached maximal ALP, while groups in BM- did not reach maximal ALP activity. Groups cultured in $\mathrm{BM}+$ containing rhBMP (BMP+) showed a significant increase $(\mathrm{P}<0.001)$ only in the second week compared to the $\mathrm{BMP}+\mathrm{EtOH}$ control, and by week three all groups displayed low levels of ALP activity (Fig. 1C). While groups cultured in $\mathrm{BM}+$ continued to increase in ALP activity throughout the 3-week culture period, $\mathrm{BM}+$ reached a peak in between weeks 1 and 3, and began to decline in between weeks 2 and 3.

The primary function of osteoblasts is to produce and maintain mineralized ECM. For our samples cultured in BM- with or without vitamin $\mathrm{D}$ metabolites, vita $_{3}$ and $1,25 \mathrm{OH}_{2} \mathrm{D}_{3}$, calcium deposition was significantly greater $(\mathrm{P}<$ $0.001)$ in cultures containing either of the vitamin D metabolites compared with the BM- ethanol control (Fig. 2). OPC1 cultured in $\mathrm{BM}+$ with or without the vitamin D metabolites showed a significantly higher amount of calcium deposition $(\mathrm{P}<0.001)$ throughout the 3 -week culture period compared to that of cultures in BM-. Cultures containing either vitaD or $1,25 \mathrm{OH}_{2} \mathrm{D}_{3}$ were significantly higher $(\mathrm{P}<0.001)$ than the $\mathrm{BM}+\mathrm{EtOH}$ control by the third week of culture (Fig. $3)$. Cultures containing rhBMP $(\mathrm{BMP}+)$ showed a statistically significant amount of calcium deposition $(\mathrm{P}<0.001)$ compared to that of the groups cultured in $\mathrm{BM}$ - throughout the 3-week culture period. The presence of vitaD $\mathrm{D}_{3}$ in $\mathrm{BMP}+$ medium caused a larger amount of calcium deposition ( $\mathrm{P}$ $<0.01$ ) compared to that of the BMP+ EtOH control, and slightly more deposition $(\mathrm{P}<0.05)$ when in the presence of $1,25 \mathrm{OH}_{2} \mathrm{D}_{3}$ (Fig. 4).

As mentioned, CYP27A1 and CYP27B1 are hydroxylases demonstrated to be involved in the metabolism of vitaD $\mathrm{D}_{3}$ to $25 \mathrm{OHD}_{3}$, and convert $25 \mathrm{OHD}_{3}$ to $1,25 \mathrm{OH}_{2} \mathrm{D}_{3}$, respectively. Here, OPC1 expressed both CYP27A1 (Fig. 5A) and CYP27B1 (Fig. 5B) in response to the presence of vi$\mathrm{taD}_{3}$, relative to the $\mathrm{BM}-\mathrm{EtOH}$ control. Increases in both 
A

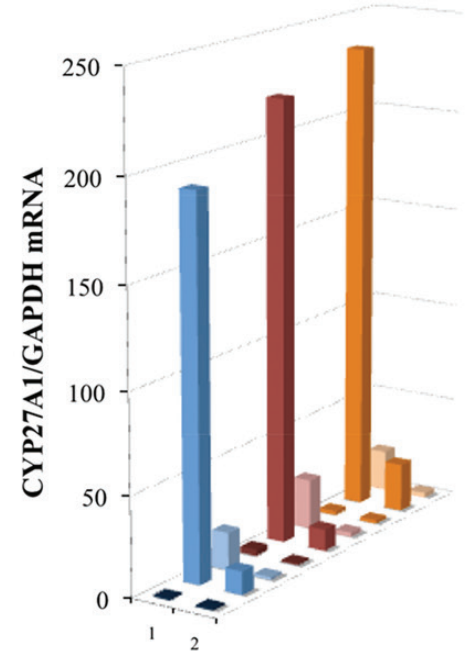

Time (Weeks)
- BM-

= $\mathrm{BM}-$ VitaD3+

= $\mathrm{BM}-1,25 \mathrm{OH} 2 \mathrm{D} 3+$

- $\mathrm{BM}+$

- $\mathrm{BM}+\mathrm{VitaD} 3+$

= $\mathrm{BM}+1,25 \mathrm{OH} 2 \mathrm{D} 3+$

- $\mathrm{BMP}+$

- $\mathrm{BMP}+\mathrm{VitaD} 3+$

$\mathrm{BMP}+1,25 \mathrm{OH} 2 \mathrm{D} 3+$
B

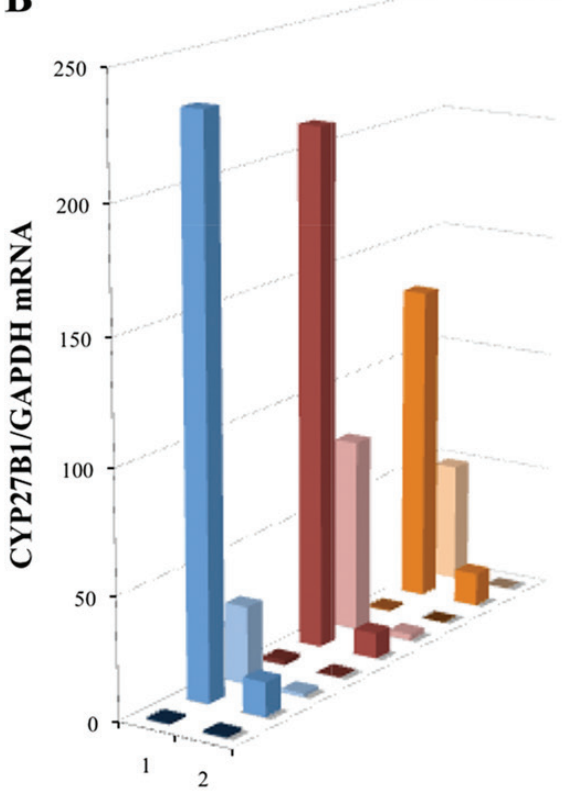

Time (Weeks)

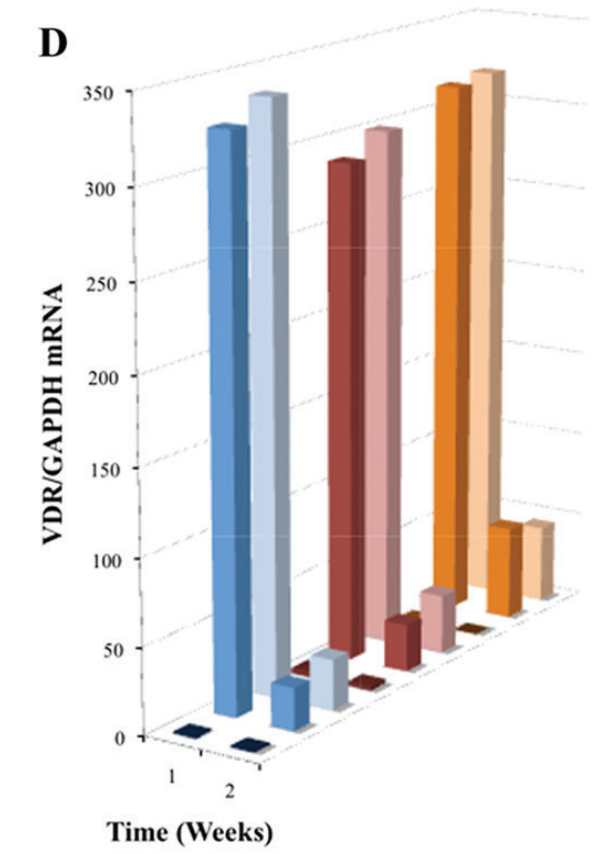

Time (Weeks)

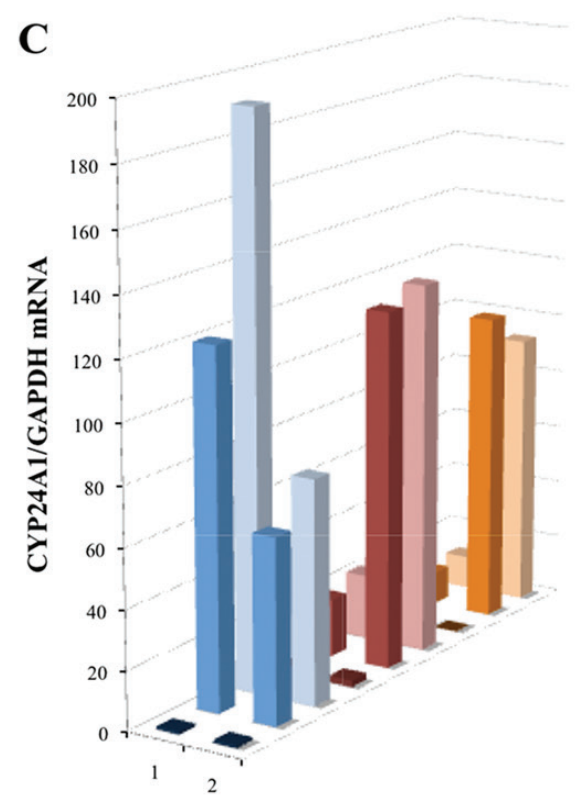

Time (Weeks)

Figure 5. Induced mRNA expression of (A) CYP27A1, (B) CYP27B1, (C) CYP24A1 and (D) VDR in nine treatment group cultures of OPC1s including either vitamin $\mathrm{D}_{3}$ or $1,25 \mathrm{OH}_{2} \mathrm{D}_{3}$ in standard bone medium (BM-) and medium containing osteogenic factors $(\mathrm{BM}+$ and $\mathrm{BMP}+)$. Total RNA was isolated and examined by quantitative RT-PCR. Data were normalized by the level of glyceraldehyde 3-phosphate dehydrogenase (GAPDH), a protein-coding gene. The figure legend for (A) applies to Fig. 5 and 6 where the bars (front to back) are associated with the listed experimental groups (top to bottom).

hydroxylases occurred in some of the treatment within the first $72 \mathrm{~h}$ of treatment (treatment added on day 4 of culture) as measured at week one, but decreased dramatically by the second week in the continuous presence of $\operatorname{vitaD}_{3}$. In the groups containing osteogenic factors $(\mathrm{BM}+$ and $\mathrm{BMP}+)$, the expression of CYP27A1 was higher then in the BM- group treated with vitaD ${ }_{3}$. However, in groups treated with $\mathrm{BMP}+$, CYP27B1 expression was lower then in the BM- and BM+ 
A

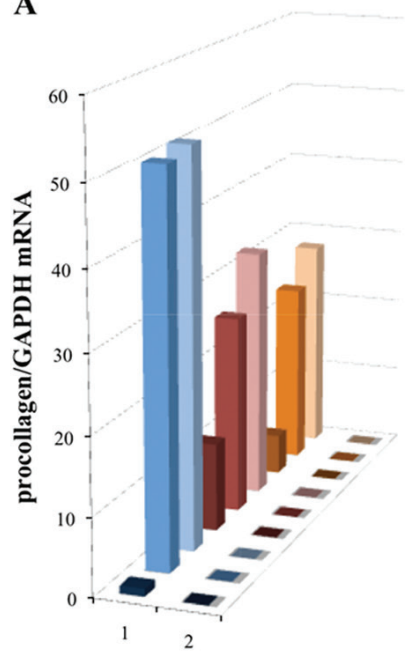

Time (Weeks)
B

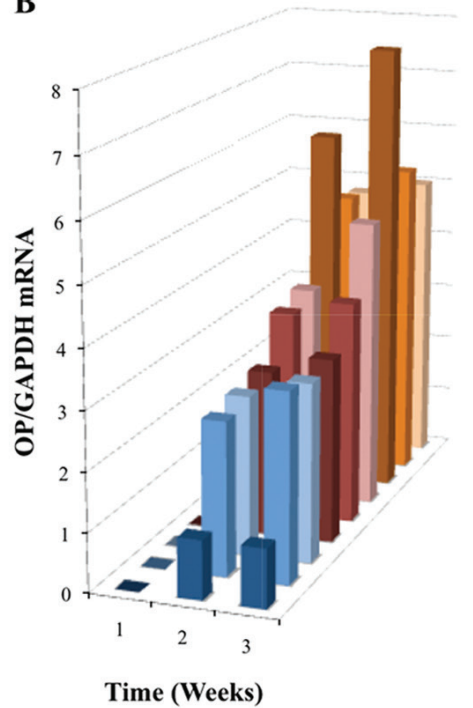

C

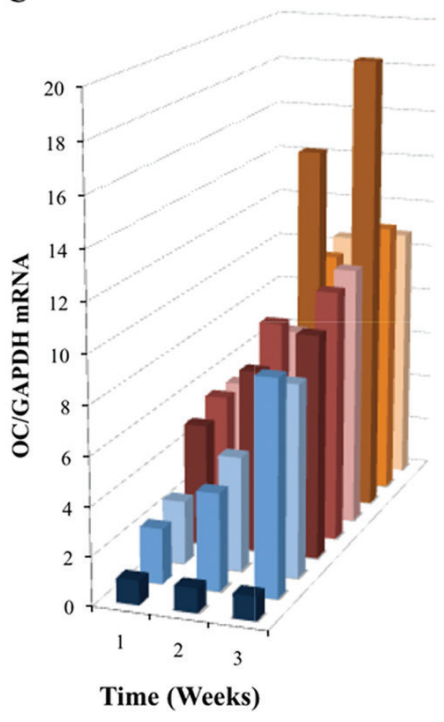

Figure 6. Induced mRNA expression of (A) proColl, (B) OP and (C) OC in nine treatment group OPC1 cultures containing the vitamin $D$ metabolites and/or osteogenic factors (see the figure legend for Fig. 5A). Total RNA was isolated and examined by quantitative RTPCR and data were again normalized by levels of GAPDH.

groups treated with vitaD $\mathrm{D}_{3}$. OPC1 also expressed CYP24A1 and VDR mRNA in response to vitaD $\mathrm{D}_{3}$ and $1,25 \mathrm{OH}_{2} \mathrm{D}_{3}$ (Fig. $5 \mathrm{C}, \mathrm{D})$. In the first week, all groups treated with the vitamin $\mathrm{D}$ metabolites had significant increases $(\mathrm{P}<0.001)$ in both CYP24A1 and VDR expression relative to the BM- control. $\mathrm{BM}$ - cultures treated with vitaD $\mathrm{D}_{3}$ expressed a much higher amount of CYP24A1 mRNA relative to BM- control, compared to the cultures containing osteogenic factors. After the continuous presence of vitaD $\mathrm{D}_{3}$, in the second week of culture, CYP24A1 expression decreased for the BM- groups, but increased in groups containing $\mathrm{BM}+$ and $\mathrm{BMP}+$. All groups treated with vitaD $\mathrm{D}_{3}$ and $1,25 \mathrm{OH}_{2} \mathrm{D}_{3}$ had statistically more VDR mRNA expression $(\mathrm{P}<0.001)$ relative to the $\mathrm{BM}$ - control during the first week of culture, but which decreased by the second week.

Synthesis of procollagen type I (proColI) is known to precede the production of collagen type I (ColI), a major component of bone ECM. This synthesis is enhanced during early osteoblast differentiation, while OC and OP are associated with later stages of osteoblast differentiation and bone development. Real-time PCR analysis showed a significant increase in proColI mRNA expression $(\mathrm{P}<0.001)$ during the first week of OPC1 culture in all groups relative to the $\mathrm{BM}$ - control, and a higher increase with treatment groups containing either vitaD $\mathrm{D}_{3}$ or $1,25 \mathrm{OH}_{2} \mathrm{D}_{3}$ (Fig. 6A). There was no statistically significant expression of proColI mRNA in the second week in any of the culture groups $(\mathrm{P}>0.05)$. In contrast to the expression of proColI, OP mRNA expression was not seen in the first week of culture time in any of the groups and increased in both the second and third week of culture relative to the BM- control (Fig. 6B). The BMP+ control without vitamin D displayed the highest OP mRNA expression relative to the BM- control. Similar to OP mRNA expression, expression of OC mRNA was highest in the $\mathrm{BMP}+$ control group, but was increased in all groups relative to the BM- control (Fig. 6C). However, in contrast to OP mRNA expression, OC mRNA expression was increased in the first week, and continued to increase during the 3-week culture period.

\section{Discussion}

In this study, an engineered OPC1 was used to examine the effect of vitamin $\mathrm{D}$ metabolites, vitaD ${ }_{3}$ and $1,25 \mathrm{OH}_{2} \mathrm{D}_{3}$, on the maturation and mineralization of culture-expanded cells as a model for bone development. In comparison to the untreated cells, vitamin D metabolites in combination with ascorbic acid, $\beta$-glycerophosphate, dex and/or BMP2 , produced more calcium deposition and showed a greater increase in ALP over time. Cultures containing osteogenic factors varied in ALP activity depending on the presence of rhBMP-2. In addition to ALP activity and calcium deposition, mRNA expression of proColI, OC and OP were analyzed over the 3-week culture period, as well as the mRNA expression of genes associated with vitamin $\mathrm{D}$ action and metabolism.

Osteoblasts are bone-forming cells derived from multipotential progenitor cells within the bone marrow stroma that also are capable of committing to other mesenchymal 
lineages, including fibroblasts, myoblasts, chondrocytes, adipocytes and osteoblasts [3, 30]. Once precursors have committed to a specific lineage, tissue specific molecules are expressed. Phenotypical characteristics of an osteoblast include the synthesis and mRNA expression of $\operatorname{proCol} I$ preceding $\mathrm{Col} I$, OC, OP, VDR, increased ALP activity and the ability to mineralize ECM. When osteoblast precursors commit to the osteoblastic lineage, the osteoblasts express bone matrix protein genes at different expression levels depending on the maturation level of the cells [31]. For example, immature mesenchymal cells and preosteoblasts weakly express ColI and collagen type II (ColII), while immature osteoblasts express OP, and bone sialoprotein (BSP), a component of mineralized tissues. Mature osteoblasts meanwhile strongly express OC [31] and may eventually become osteocytes when they are embedded into the bone matrix and express dentin matrix protein 1 (DMP-1).

In vitro human osteoblasts respond to exogenous $1,25 \mathrm{OH}_{2} \mathrm{D}_{3}$ by decreasing their rate of proliferation while increasing their expression of mRNA of osteogenic biomarkers such as OC and OP. While it has been known that circulating vitamin $\mathrm{D}$ is derived from the kidneys, recently a number of studies have demonstrated the extra-renal synthesis of $1,25 \mathrm{OH}_{2} \mathrm{D}_{3}$ from $25 \mathrm{OHD}_{3}$ in skin, liver, lymph nodes, activated monocytes/macrophages, dendritic cells and osteoblasts [11]. In contrast to extra-renal metabolism of $25 \mathrm{OHD}_{3}$ to $1,25 \mathrm{OH}_{2} \mathrm{D}_{3}$, there have been occasional reports of extrahepatic metabolism of vitaD $\mathrm{D}_{3}$, but no detailed analysis until now. Recently, we demonstrated that OPC1 could metabolize vitaD $\mathrm{D}_{3}$ to $1,25 \mathrm{OH}_{2} \mathrm{D}_{3}$ in a dose-dependent manner [6], and in this present experiment, we were able to demonstrate the upregulation of mRNA expression of vitamin D associated hydroxylases CYP27A1, CYP27B1 and CYP24A1, as well as VDR in response to vitaD ${ }_{3}$. It was also demonstrated that vitaD $\mathrm{D}_{3}$ influenced the expression of osteogenic mRNA proColI, OC and OP in the same manner as $1,25 \mathrm{OH}_{2} \mathrm{D}_{3}$.

In addition to the effects of vitamin $\mathrm{D}$ metabolites on OPC1, vitamin D in combination with common osteogenic factors was investigated. It was demonstrated that in combination with these osteogenic factors, matrix maturation and mineralization were significantly increased. However, there were differential results in bone maturation associated with ALP activity seen in cultures treated with BMP+. ALP expression is associated with bone cell phenotype, and in heavily mineralized cultures, cellular levels of ALP decline [32]. OPC1 cultured in BMP+ with or without vitamin $\mathrm{D}$ metabolites demonstrated an increase in mineralization, and consequently with the mRNA expression of OC and OP, proteins that are known to increase with the accumulation of mineralization, compared to the BM- and BM+ groups. These results indicate that rhBMP-2 had a major influence on OPC1 bone mineralization, that may exceed the influence of vitamin D. A major limitation to this result, was that $\mathrm{BMP}+$ cultures were so heavily mineralized that by day 17 of culture time, the monolayer began to detach from the culture vessel.

It has been previously demonstrated that using dex, BMP-2 and $1,25 \mathrm{OH}_{2} \mathrm{D}_{3}$ tend to enhance a more differentiated osteoblast phenotype [33]. However in our study, OP and $\mathrm{OC}$ mRNA expression in groups treated with vitaD $\mathrm{D}_{3}$ or $1,25 \mathrm{OH}_{2} \mathrm{D}_{3}$ and $\mathrm{BMP}+$ was slightly lower than the BMP+ control, but higher than the osteogenic medium containing vitamin $\mathrm{D}$ metabolites and no BMP (BM+). This may be because we used a higher dose of $1,25 \mathrm{OH} 2 \mathrm{D} 3$, which would also explain the very significant increase in catabolic enzyme mRNA expression of CYP24A1 seen in the second week of culture. In addition, it could be postulated that as a regulator of ECM mineralization, vitamin D dampened the effects of BMP. Many in vitro vitamin D studies investigating the antiproliferative and pro-differentiative effects of vitamin D are short-term and use a supra-physiological dose; however, for long-term cultures using vitamin D as an osteognenic factor, it may be beneficial to use a dose that more closely resembles the phsyiological dose.

It has been long recognized that long-term or excessive use of glucocorticoids (GC), whether from endogenous hypersecretion or iatrogenically, manifests adverse skeletal effects such as osteoporosis [34]. In human subjects receiving long-term GC treatment, bone loss is associated with the decrease in overall bone formation rate and in the mean thickness of the walls on newly synthesized trabecular bone, a pattern consistent with the decrease in number and/or activity of osteoblasts rather than the increase in number and/ or activity of osteoblasts [34]. Paradoxically, several studies have demonstrated that treating cells derived from human bone with GCs promotes osteogenic differentiation, and has been proposed as a standard supplement for the ex vivo expansion of cells with osteogenic potential for use in tissue reconstruction and repair [34]. Dexamethasone is a GC that is commonly used as an inducer of bone marrow stromal cell differentiation, which reliably stimulates the development of many, but not all, phenotypic features of human osteoblasts [33]. However, GCs have deleterious effects in vivo, resulting in inhibition of osteoblast function. BMP-2 is another inducer of osteoblast differentiation, and is essential for postnatal bone formation. BMP-2 has been used to induce osteoblast differentiation in vitro in many human and animal models, and is believed to provide a more physiologic stimulus than dexamethasone; however, it appears to enhance a more mature osteoblast characteristic [33].

Overall, this work provided baseline two-dimensional culture data characterizing the interaction between vitamin D metabolites and an osteoprecursor cell line. Ongoing efforts are expanding this approach into a tissue engineered model created with three-dimensional culture and custom biomaterial scaffolds including the application of mechanical stimulation through access to a novel bioreactor [2]. In addition, the combined influence of vitamin D and biomechanics 
on isolated single cells within an optofluidic environment is concurrently being investigated. This active research theme addresses multiscale mechanotransduction through novel bioengineering approaches.

\section{Acknowledgement}

The authors appreciate the generous support given by fellow laboratory members in the Department of Molecular and Medical Genetics, Oregon Health and Science University, and the constructive comments made by Drs. Michael S. Bartlett, Susan E. Masta and David H. Peyton.

\section{Grant Support}

National Institutes of Health (Grant HD081308) and the Collins Medical Trust.

\section{References}

1. Buttery LD, Bourne S, Xynos JD, Wood H, Hughes FJ, Hughes SP, Episkopou V, et al. Differentiation of osteoblasts and in vitro bone formation from murine embryonic stem cells. Tissue Eng. 2001;7(1):89-99.

2. Mason SS, Kohles SS, Zelick RD, Winn SR, Saha AK. Three-Dimensional Culture of Cells and Matrix Biomolecules for Engineered Tissue Development and Biokinetics Model Validation. J Nanotechnol Eng Med. 2011;2(2):25001-25007.

3. Hicok KC, Thomas T, Gori F, Rickard DJ, Spelsberg TC, Riggs BL. Development and characterization of conditionally immortalized osteoblast precursor cell lines from human bone marrow stroma. J Bone Miner Res. 1998;13(2):205-217.

4. Huang YL, Qiu RF, Mai WY, Kuang J, Cai XY, Dong YG, Hu YZ, et al. Effects of insulin-like growth factor-1 on the properties of mesenchymal stem cells in vitro. $\mathrm{J}$ Zhejiang Univ Sci B. 2012;13(1):20-28.

5. Winn SR, Randolph G, Uludag H, Wong SC, Hair GA, Hollinger JO. Establishing an immortalized human osteoprecursor cell line: OPC1. J Bone Miner Res. 1999;14(10):1721-1733.

6. Mason SS, Kohles SS, Winn SR, Zelick RD. Extrahepatic 25-Hydroxylation of Vitamin D3 in an Engineered Osteoblast Precursor Cell Line Exploring the Influence on Cellular Proliferation and Matrix Maturation During Bone Development. ISRN Biomed Eng. 2013;(1):956362 (11pp).

7. Morris HA, Anderson PH. Vitamin D metabolism and biological activities. Mol Cell Endocrinol. 2011;347(1-
2):1-2.

8. Brannon PM. Key questions in vitamin D research. Scand J Clin Lab Invest Suppl. 2012;243:154-162.

9. Hobaus J, Thiem U, Hummel DM, Kallay E. Role of calcium, vitamin D, and the extrarenal vitamin D hydroxylases in carcinogenesis. Anticancer Agents Med Chem. 2013;13(1):20-35.

10. Jones G, Strugnell SA, DeLuca HF. Current understanding of the molecular actions of vitamin D. Physiol Rev. 1998;78(4):1193-1231.

11. Atkins GJ, Anderson PH, Findlay DM, Welldon KJ, Vincent C, Zannettino AC, O'Loughlin PD, et al. Metabolism of vitamin D3 in human osteoblasts: evidence for autocrine and paracrine activities of 1 alpha,25-dihydroxyvitamin D3. Bone. 2007;40(6):1517-1528.

12. Ahmed MS, Shoker A. Vitamin D metabolites; protective versus toxic properties: molecular and cellular perspectives. Nephrol Rev. 2010;2(1):e5.

13. Norman AW. Sunlight, season, skin pigmentation, vitamin $\mathrm{D}$, and 25-hydroxyvitamin D: integral components of the vitamin D endocrine system. Am J Clin Nutr. 1998;67(6):1108-1110.

14. Trump DL, Deeb KK, Johnson CS. Vitamin D: considerations in the continued development as an agent for cancer prevention and therapy. Cancer J. 2010;16(1):19.

15. Yamamoto Y, Yoshizawa T, Fukuda T, Shirode-Fukuda Y, Yu T, Sekine K, Sato T, et al. Vitamin D receptor in osteoblasts is a negative regulator of bone mass control. Endocrinology. 2013;154(3):1008-1020.

16. Seiffert M, Rech M, Meineke V, Tilgen W, Rechrath J. Differential biological effects of 1,25-dihydroyxy Vitamin D3 on melanoma cell lines in vitro. J Steroid Biochem Molec Bio. 2004:89-90:375-379.

17. Flanagan JN, Young MV, Persons KS, Wang L, Mathieu JS, Whitlatch LW, Holick MF, et al. Vitamin D metabolism in human prostate cells: implications for prostate cancer chemoprevention by vitamin D. Anticancer Res. 2006;26(4A):2567-2572.

18. Holick MF. Vitamin D: extraskeletal health. Endocrinol Metab Clin North Am. 2010;39(2):381-400, table of contents.

19. Naeem Z. Vitamin d deficiency- an ignored epidemic. Int J Health Sci (Qassim). 2010;4(1):V-VI.

20. Geng S, Zhou S, Glowacki J. Effects of 25-hydroxyvita$\min \mathrm{D}(3)$ on proliferation and osteoblast differentiation of human marrow stromal cells require CYP27B1/1alphahydroxylase. J Bone Miner Res. 2011;26(5):1145-1153.

21. Chen G, Kim SH, King AN, Zhao L, Simpson RU, Christensen PJ, Wang Z, et al. CYP24A1 is an independent prognostic marker of survival in patients with lung adenocarcinoma. Clin Cancer Res. 2011;17(4):817-826.

22. Boyan BD, Hummert TW, Dean DD, Schwartz Z. Role of material surfaces in regulating bone and cartilage cell 
response. Biomaterials. 1996;17(2):137-146.

23. Armbrecht HJ, Hodam TL, Boltz MA, Partridge NC, Brown AJ, Kumar VB. Induction of the vitamin D 24-hydroxylase (CYP24) by 1,25-dihydroxyvitamin D3 is regulated by parathyroid hormone in UMR106 osteoblastic cells. Endocrinology. 1998;139(8):3375-3381.

24. Parise RA, Egorin MJ, Kanterewicz B, Taimi M, Petkovich M, Lew AM, Chuang SS, et al. CYP24, the enzyme that catabolizes the antiproliferative agent vitamin $\mathrm{D}$, is increased in lung cancer. Int J Cancer. 2006;119(8):18191828.

25. Boyan BD, Chen J, Schwartz Z. Mechanism of Pdia3dependent 1alpha,25-dihydroxy vitamin D3 signaling in musculoskeletal cells. Steroids. 2012;77(10):892-896.

26. Bouillon R, Carmeliet G, Verlinden L, van Etten E, Verstuyf A, Luderer HF, Lieben L, et al. Vitamin D and human health: lessons from vitamin $\mathrm{D}$ receptor null mice. Endocr Rev. 2008;29(6):726-776.

27. Boyan BD, Schwartz Z, Bonewald LF, Swain LD. Localization of 1,25-(OH)2D3-responsive alkaline phosphatase in osteoblast-like cells (ROS 17/2.8, MG 63, and $\mathrm{MC}$ 3T3) and growth cartilage cells in culture. J Biol Chem. 1989;264(20):11879-11886.

28. Hoemann CD, El-Gabalawy H, McKee MD. In vitro osteogenesis assays: influence of the primary cell source on alkaline phosphatase activity and mineralization. Pathol Biol (Paris). 2009;57(4):318-323.
29. Zhou S, Glowacki J, Kim SW, Hahne J, Geng S, Mueller $\mathrm{SM}$, Shen L, et al. Clinical characteristics influence in vitro action of 1,25-dihydroxyvitamin $\mathrm{D}(3)$ in human marrow stromal cells. J Bone Miner Res. 2012;27(9):19922000.

30. Swolin-Eide D. Studies of human osteoblast-like cellseffects of growth hormone and steroids. J Int Fed Clin Chem Lab Med. 2002;13(4):1-7.

31. Komori T. Regulation of bone development and extracellular matrix protein genes by RUNX2. Cell Tissue Res. 2010;339(1):189-195.

32. Lian JB, Stein GS. Concepts of osteoblast growth and differentiation: basis for modulation of bone cell development and tissue formation. Crit Rev Oral Biol Med. 1992;3(3):269-305.

33. Jorgensen NR, Henriksen Z, Sorensen OH, Civitelli R. Dexamethasone, BMP-2, and 1,25-dihydroxyvitamin D enhance a more differentiated osteoblast phenotype: validation of an in vitro model for human bone marrowderived primary osteoblasts. Steroids. 2004;69(4):219226.

34. Walsh S, Jordan GR, Jefferiss C, Stewart K, Beresford $\mathrm{JN}$. High concentrations of dexamethasone suppress the proliferation but not the differentiation or further maturation of human osteoblast precursors in vitro: relevance to glucocorticoid-induced osteoporosis. Rheumatology (Oxford). 2001;40(1):74-83. 